Article

\title{
Phenotypic Plasticity Promotes Overwintering Survival in A Globally Invasive Crop Pest, Drosophila suzukii
}

\author{
Dara G. Stockton ${ }^{1, *}$, Anna K. Wallingford ${ }^{2}$ and Gregory M. Loeb ${ }^{1}$ \\ 1 Department of Entomology, Cornell AgriTech and New York State Agricultural Experiment Station, \\ Cornell University, Geneva, NY 14456, USA; gme1@cornell.edu \\ 2 Invasive Insect Biocontrol and Behavior Laboratory, USDA-ARS, Beltsville, MD 20705, USA; \\ annawllngfrd@gmail.com \\ * Correspondence: dara.stockton@cornell.edu; Tel.: +1-956-279-3210
}

Received: 19 July 2018; Accepted: 17 August 2018; Published: 21 August 2018

\begin{abstract}
Spotted wing drosophila, Drosophila suzukii Matsumura, is a major pest of small fruit worldwide in temperate and subtropical growing regions. In Northern climates, D. suzukii likely overwinters locally under leaf litter and snow pack, but our understanding of the factors affecting thermal susceptibility is limited. While previous investigations of thermal susceptibility in this species have employed conventional static acclimation protocols, we aimed to determine whether gradual cooling, or dynamic acclimation, may extend the limits of known thermal tolerance by more closely approximating naturally occurring shifts in temperature. First, we assessed survival among adult and pupal D. suzukii using static acclimation. Then, we re-assessed survival using a novel dynamic acclimation method. We found that while static acclimation was sufficient to induce cold tolerance, dynamic acclimation significantly improved survival at temperatures as low as $-7.5^{\circ} \mathrm{C}$. Following static acclimation, the lower lethal limit of adult D. suzukii was $-1.1^{\circ} \mathrm{C}$ in winter morphotype (WM) adults compared to $1.7^{\circ} \mathrm{C}$ in non-acclimated summer morphotype (SM) adults. Dynamic acclimation reduced the lower limit to $-5^{\circ} \mathrm{C}$ in SM flies. At the end of our study $50 \%$ of WM flies survived $72 \mathrm{~h}$ at $-7.5^{\circ} \mathrm{C}$. Below $0{ }^{\circ} \mathrm{C}$ pupal survival declined significantly regardless of acclimation procedure. However, pupal acclimation improved survival outcomes significantly compared to non-acclimated pupae, suggesting that while juvenile diapause is unlikely, cold hardening likely benefits those flies which may develop into the overwintering WM population. These data suggest that the degree of cold hardening is proportional to the thermal environment, a finding previously unrecognized in this species. Given the economic impact of this pest, these data may have important implications for offseason population monitoring and management. We discuss how phenotypic plasticity may drive geographical range expansion, and the impact of climate change on the spread of this species.
\end{abstract}

Keywords: spotted wing drosophila; SWD; cold hardening; acclimation; small fruit; physiology; winter morph

\section{Introduction}

Spotted wing drosophila, Drosophila suzukii Matsumura (Diptera: Drosophilidae), is a major invasive pest of small fruit crops in North America, South America, and Europe [1-4], with potential to spread to Africa and Oceania [4]. Unique among its sister Drosophilids in the melanogaster group, this species, which originated in Northeast Asia, possesses a serrated ovipositor used for oviposition into ripening and unripe fruit [5-8]. As such, D. suzukii is responsible for significant economic losses 
in small fruit crops worldwide, including raspberries, blueberries, strawberries, and cherries $[9,10]$. In Northern climates, D. suzukii reaches peak populations in the summer, which coincides with warm temperatures and peak fruit abundance [5,11-13]. Subsequently, populations decline in the winter, and detection is often difficult until temperatures increase again in the spring. Winter trapping studies in Europe and North America have captured D. suzukii despite periods below $0{ }^{\circ} \mathrm{C}[11,14,15]$, suggesting that D. suzukii may overwinter locally, similar to D. melanogaster [16-19]. The time of first capture varies yearly and regionally, and is presumably affected by the degree and duration of extreme cold temperatures to which the insects were exposed the previous winter. However, the behavioral and physiological mechanisms by which this relatively cold-intolerant insect [20-22] survives harsh winters remains unclear.

At both high and low temperatures, physiological functions in D. suzukii, including larval development and reproduction, become dysregulated [14,23-26]. However, phenotypic plasticity and the development of certain traits in response to winter weather conditions appears to be an important thermoregulatory survival strategy common among many temperate Drosophilids [27-29]. Whereas summer-morphotype (SM) flies develop under conditions of long day length and warm temperatures, winter-morphotype (WM) traits, including longer wing length, larger bodies, and darker cuticular pigmentation, occur when reared under cool conditions $\left(10-15^{\circ} \mathrm{C}\right)[5,11,22,30-34]$. The traits associated with WM flies appear adaptive and allow the insect to absorb and retain heat throughout the winter [35-38], although reduced water loss and improved immune function have also been documented [34].

WM flies consistently display improved recovery and longevity at cold temperatures compared to SM flies [31-33]. Indeed, bioinformatics data indicates changes in ion transport and carbohydrate metabolism among WM Drosophilids [30,32,34,39], consistent with physiological cold tolerance and the prevention of ice crystal formation within the haemocoel $[40,41]$. However, this species appears to be relatively freeze intolerant $[20,31,42]$, and appears to employ a freeze-avoidant strategy similar to most other Drosophilids [43]. One study observed cold shock survival at temperatures below $0{ }^{\circ} \mathrm{C}$ for up to $1 \mathrm{~h}$ and found $-7.5^{\circ} \mathrm{C}$ to be the lower lethal limit [20]. Another identified supercooling points near $-20^{\circ} \mathrm{C}$, although the exposure period at these temperatures was approximately 1 second [31]. In contrast, freeze tolerant species are known to survive temperatures as low as $-40{ }^{\circ} \mathrm{C}$ for extended durations [44].

There are currently no known reports of juvenile overwintering by larval or pupal D. suzukii and juvenile overwintering is generally uncommon among temperate Drosophilids [37]. Many reports suggest lesser tolerance among larvae and pupae compared to adults, and little survival at temperatures below $5{ }^{\circ} \mathrm{C}[22,31,37,45,46]$. One recent study reported an $\mathrm{Lt}_{50}$ of $21 \mathrm{~h}$ for pupae at $5{ }^{\circ} \mathrm{C}$ [46]. However, the pupae were not acclimated, and it is unclear how developmental acclimation may affect their survival. There are select temperate Drosophilids which do overwinter in juvenile form, including Chymomyza costata Zetterstedt, a holarctic species which is found in the Northern United States, Canada, and Europe [47], and is known to undergo functional larval diapause [43,44,48]. Interestingly, gradual cooling appears to play an important role in the freeze tolerant response of C. costata [49].

Previous investigations into the thermal susceptibility of $D$. suzukii have used conventional static acclimation protocols, in which the insect is kept at a single constant cool temperature, typically $10-15{ }^{\circ} \mathrm{C}$, for the duration of the acclimation period prior to testing [20,22,31-33,50]. To our knowledge, there is no research on gradual cold hardening, or dynamic acclimation, in D. suzukii; and the effect this may have on our estimations of thermal susceptibility - whether acclimatization at temperatures below $10{ }^{\circ} \mathrm{C}$ would extend the known thermal tolerance limits identified in this species-remains unknown. The plasticity of thermal thresholds among arthropods is certainly documented [51,52], particularly among those found near the poles [53]. Exposure to extreme temperatures during a critical acclimation period is often sufficient to adaptively [52] shift chill coma and coordination thresholds, as well as to reduce the lower lethal limit of the organism [53]. In D. suzukii, although $10-15^{\circ} \mathrm{C}$ is sufficient to induce WM traits, the physiological changes associated with extreme cold hardening (i.e., freeze tolerance) 
may require longer durations at cooler temperatures than has been explored. This is significant because in nature, cooling tends to occur incrementally over time, providing opportunity to make physiological and behavior modifications potentially important for survival [54,55].

Our aim in this study was to further the discussion of overwintering potential in D. suzukii and revise our current estimations of thermal susceptibility in D. suzukii with consideration for dynamic acclimation and physiological plasticity. Broadly, we compared survival following static vs dynamic acclimation in response to short and long-term cold exposure durations. We also aimed to re-evaluate the overwintering potential of juvenile $D$. suzukii, addressing acclimation effects within the context of survival and development. Because the degree of cold hardening is theoretically proportional to experience with cool temperatures [21,56-58], we hypothesized that a gradual reduction in temperature would enhance cold hardening and possibly confer freeze tolerance. Our dynamic acclimation method is a novel approach to studying thermal susceptibility in D. suzukii and may provide a more accurate estimate of overwintering potential of $D$. suzukii than previous reports. Given the wide geographic distribution of D. suzukii, and the threat of range expansion due to climate change [59-62], it may be increasingly important to understand physiological plasticity in order to predict the long-term expansion potential $[50,63]$ of this species.

\section{Materials and Methods}

\subsection{Insect Colony}

For the laboratory assays described here, the SM D. suzukii colony was maintained at the Cornell AgriTech facility in Geneva, NY. The colony was established from wild caught flies captured on farms near Geneva, New York. The original colony began in 2011, and in 2014, 2016, and 2017, additional wild flies were added to the colony to help maintain genetic diversity. The captures occurred during the summer months of June-September, when wild populations were highest. The colony was maintained on a standard cornmeal diet [64] in 8 oz. polypropylene fly rearing bottles (VWR ${ }^{\circledR}$ International; Radnor, PA, USA). The diet was replaced weekly to ensure colony health. The colony was maintained in a climate-controlled growth chamber set to $25{ }^{\circ} \mathrm{C}$, with a $14 \mathrm{~L}$ : $10 \mathrm{D}$ photoperiod, and $65 \%$ relative humidity (r.h.) to simulate "summer conditions" [33].

\subsection{Static Susceptibility in Adults}

First we investigated the extent to which static acclimation may confer protection against chronic cold exposure in adults. We directly compared cold tolerances in the three most commonly reported phenotypes associated with conventional static acclimation studies: (1) developmentally acclimated WM flies, (2) SM flies acclimated as adults, and (3) non-acclimated SM flies. This allowed us to measure thermal susceptibility in a manner similar to that previously reported [20,22,31-33].

We used a within-subject experimental design and exposed adults to six different temperatures $\left(4.4,1.7,-1.1,-3.9,-6.7,-9.4^{\circ} \mathrm{C}\right)\left(40,35,30,25,20,15^{\circ} \mathrm{F}\right)$ for up to 4 weeks (Figure 1 A). For a given temperature treatment, the same flies were monitored at each time point. We included 3 acclimation treatments, non-acclimated SM flies (Figure 2A,C), acclimated SM flies, and developmentally acclimated WM flies (Figure 2B,D), crossed with 6 temperature levels resulting in a $3 \times 6$ factorial design. We monitored three experimental replicates among WM flies, and 5 replicates among acclimated and non-acclimated SM flies for each temperature tested (Table 1). There were approximately 25 mixed-sex flies per replicate, contained in a single fly bottle, but the total number of insects in each replicate varied slightly. The fly sex ratios were approximately equivalent in each bottle. The replicate bottles contained $50 \mathrm{ml}$ cornmeal diet as a source of nutrition, which was replaced weekly. 
Table 1. Sample sizes and replicate structure for each adult static acclimation treatment group.

\begin{tabular}{cccccccc}
\hline \multirow{2}{*}{ Acclimation } & \multirow{2}{*}{ Phenotype } & \multicolumn{5}{c}{ Total No. Insects Tested per Treatment $\mathbf{N}=$ (\#Replicates) } \\
\cline { 3 - 7 } & & $\mathbf{4 . 4}{ }^{\circ} \mathbf{C}$ & $\mathbf{1 . 7}{ }^{\circ} \mathbf{C}$ & $\mathbf{- 1 . 1}{ }^{\circ} \mathbf{C}$ & $\mathbf{- 3 . 9}{ }^{\circ} \mathbf{C}$ & $\mathbf{- 6 . 7}{ }^{\circ} \mathbf{C}$ & $\mathbf{- 9 . 4}{ }^{\circ} \mathbf{C}$ \\
\hline Yes & WM & $78(3)$ & $71(3)$ & $69(3)$ & $75(3)$ & $72(3)$ & $75(3)$ \\
Yes & SM & $131(5)$ & $142(5)$ & $130(5)$ & $138(5)$ & $124(5)$ & $125(5)$ \\
No & SM & $129(5)$ & $127(5)$ & $127(5)$ & $135(5)$ & $108(5)$ & $125(5)$ \\
\hline
\end{tabular}

A

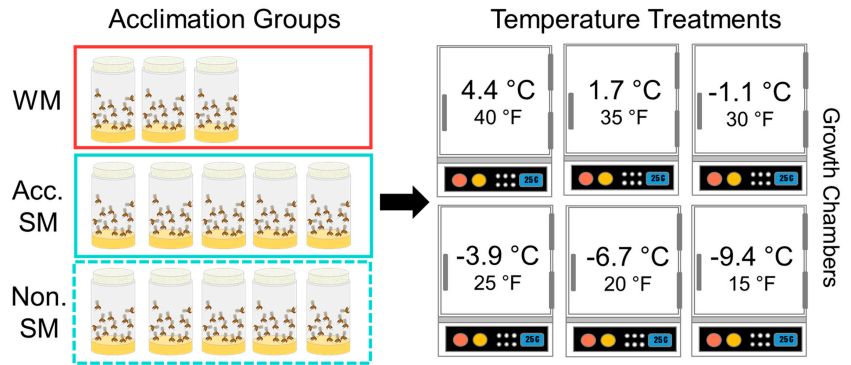

B

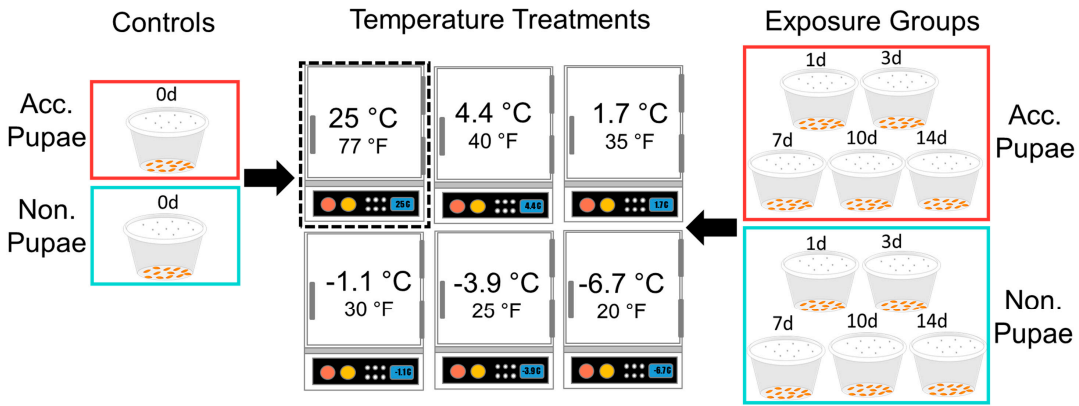

Figure 1. Experimental design of the adult (A) and pupal (B) static susceptibility tests. Group labels: "WM" refers to developmentally acclimated WM flies, "Acc. SM" refers to acclimated SM flies, and "Non. SM" refers to non-acclimated SM flies.

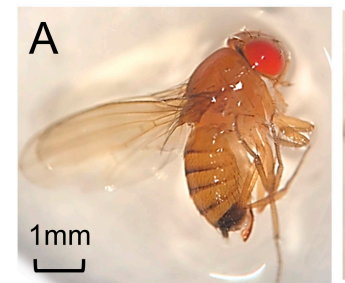

$\mathrm{E}$

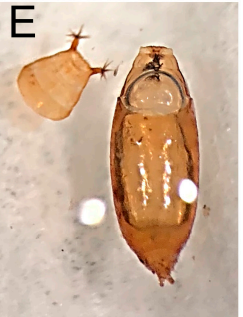

$\mathrm{F}$
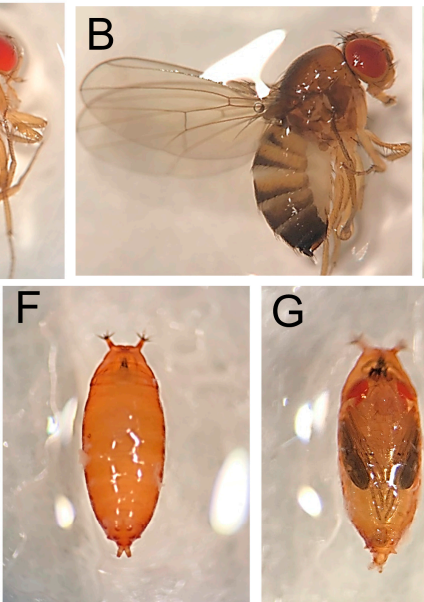

G

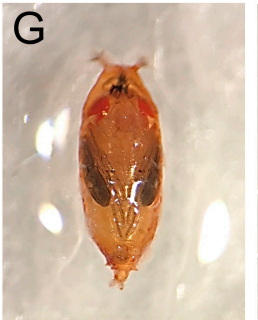

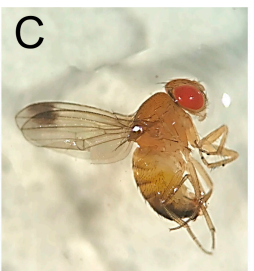

$\mathrm{H}$

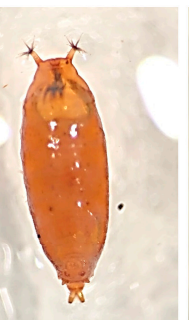

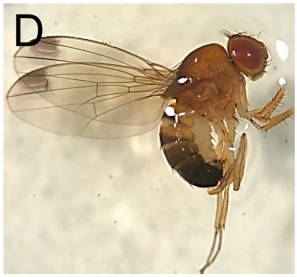

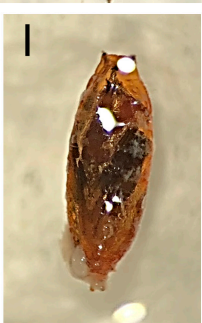

Figure 2. Differences in D. suzukii phenotypic expression of size and pigmentation when reared at warm $(\mathbf{A}, \mathbf{C})$ and cool (B,D) temperatures. Adult SM female (A), adult WM female (B), adult SM male (C), and adult WM male (D). Cast pupal case from a recently eclosed D. suzukii (E), healthy undeveloped pupa 2 days post-pupation (F), healthy developed pupa 5 days post-pupation (G), dead undeveloped pupa (H), dead developed pupa (I). 
We reared WM flies by transferring eggs to a $15^{\circ} \mathrm{C}$ incubator for the duration of development [33]. The eggs were transferred in the colony bottles in which they were laid, in a cornmeal diet agar. Development time at this temperature increased from approximately 13 days at $25^{\circ} \mathrm{C}$ to approximately 28 days. Adult $\mathrm{WM}$ flies were aged $5-7$ days at $15{ }^{\circ} \mathrm{C}$ prior to use. We induced cold-acclimated SM flies by moving newly eclosed adults to the $15^{\circ} \mathrm{C}$ incubator for 5 days. Acclimation cohorts were kept in groups of 25 flies. Temperature and humidity were regulated in six individual environmental growth chambers (model I-30BL: Percival Scientific, Inc.; Perry, IA, USA), which were monitored daily with $\mathrm{HOBO}^{\circledR}$ data loggers (model UX100-011 Temp/RH; Onset Computer Corporation, Bourne, MA, USA) to ensure the settings were accurate. The growth chambers were kept on a $10 \mathrm{~L}: 14 \mathrm{D}$ light cycle to simulate winter photoperiodic conditions. Humidity decreased to $25 \%$ r.h. to limit ice formation.

The flies were monitored for mortality at set intervals at 1, 3, 7, 10, 14, 21, and 35 days. Mortality assessments required a period of revival, particularly at the lower temperature treatments $[56,65]$. For this reason, mortality was assessed after a warm-up period. We moved the flies from their respective cold chambers into the colony room $\left(25^{\circ} \mathrm{C}\right)$ for two hours prior to assessment [29].

\subsection{Pupal Susceptibility}

Next, we assessed the effect of temperature on pupal survival and observed both survival and development at above and below $0{ }^{\circ} \mathrm{C}$ for up to two weeks and compared our results among cold-acclimated and non-acclimated pupae. We used a between-subjects experimental design and exposed pupae to cold temperatures at five temperatures $\left(4.4,1.67,-1.11,-3.87,-6.7^{\circ} \mathrm{C}\right)$ and for five exposure durations $(1,3,7,10,14$ days; Figure 1B). We compared survival at these temperatures among cold-acclimated and non-acclimated pupae. As a result, we employed a $2 \times 5 \times 5$ factorial design with two acclimation treatments, 5 temperature treatments, and 5 exposure duration treatments, for a total of 50 treatment groups with $N=25$ pupae per treatment group. Because mortality assessments required that we rear the pupae out to adults, we compared survival between groups at each individual time point. Each group was independent of the other treatments.

Cold-acclimated pupae were induced by moving eggs and 1 st instar larvae into a $15^{\circ} \mathrm{C}$ chamber for the duration of their development [37]. The light cycle in the $15^{\circ} \mathrm{C}$ chamber was set at $10 \mathrm{~L}: 14 \mathrm{D}$ with $60 \%$ r.h. Flies in the cold acclimation and non-acclimation treatments were matched for age so that pupation in both groups occurred within 1-2 days of each other. After pupation, 1-2 days old pupae from both acclimation treatments were removed from the agar in the rearing bottles and cleaned. We cleaned the pupae by carefully extracting them from the cornmeal agar of their rearing bottles using a long metal spatula. Cleaning the pupae increased our transfer survival rates (from $50 \%$ to close to $100 \%$ ). We rinsed the pupae with distilled water to clear the respiratory horns, and surface sterilized them with a rapid $95 \%$ acetone and $95 \%$ ethanol rinse, to remove any surface pathogens that could affect survival throughout the experiment. This was followed by an additional rinse with distilled water to remove any remaining acetone or ethanol on the insect cuticle. The pupae were then transferred to a paper towel to absorb excess moisture before being moved to their final destination.

The cleaned pupae were moved in groups of 25 into $95 \%$ ethanol-sterilized, $16 \mathrm{oz}$. transparent polypropylene deli cups $\left(473 \mathrm{ml}, 11.7 \times 7.6 \times 8.9 \mathrm{~cm}\right.$; Pro-Kal ${ }^{\mathrm{TM}}$ PK165-C; Fabri-Kal, Kalamazoo, MI, USA). Each cup contained a complete treatment group. All treatment groups were independent. The lid of the deli cup was perforated $10 \times$ with a small dissection probe (product No. 4751; BioQuip Products, Rancho Dominguez, CA, USA) to allow ventilation. After set-up, the pupae were immediately transferred to their respective cold growth chambers. The growth chambers were the same as those used in the adult susceptibility experiment and were kept at the same photoperiod and humidity settings.

When the designated thermal exposure time had lapsed, the pupae in their deli cups were removed from the growth chambers. Two groups, a cold-acclimated and a non-acclimated group, were removed from each temperature chamber at each time point. As a result, each time point, 10 total treatment groups were removed and transferred to an observation room, held at 25 C, 60\% r.h., 14:10 L:D. We then observed eclosion (Figure 2E) and pupal development for up to 7 days. We scored 
eclosion, including partial eclosion, as evidence of survival. Failure to eclose after 7 days indicated that the pupae had died at some point during the experiment. As a control, we also compared survival among acclimated and non-acclimated pupae without additional chill time, which were moved directly to the warm colony chamber at $25^{\circ} \mathrm{C}$ to complete development. This allowed us to assess baseline survival.

To differentiate between those pupae that continued to develop throughout the experiment, and thus survived past the point of direct thermal exposure (the point at which we moved the pupae from the cold chamber to the warm-up room), we observed the pupal development stage in all dead pupae at the end of the experiment. We marked those pupae as either undeveloped or developed. Undeveloped pupae (Figure 2F,H) were characterized by internal white or brown coloration without clear differentiation of adult tissues visible through the pupal case. Developed pupae (Figure 2G,I) had red, clearly defined eye spots and black striping along the mid-point of the pupal case indicating wing formation.

\subsection{Dynamic Acclimation}

Finally, we observed the effect of dynamic acclimation on thermal susceptibility in adult $D$. suzukii and pupae. We slowly decreased the temperature from $15^{\circ} \mathrm{C}$ to $-7.5^{\circ} \mathrm{C}$ over the course of 3 weeks, using three-day intervals for temperature reduction, and observed the survival of SM and WM adults and pupae. The temperature settings were monitored closely and adjusted daily as needed. We moved SM and WM flies into bottles in groups of approximately 15-20 flies. Each bottle represented an experimental replicate. There were $10 \mathrm{WM}$ fly bottles $(N=147$ total flies), and $10 \mathrm{SM}$ fly bottles $(N=196)$. Three additional bottles of WM $(N=43)$ and SM flies $(N=67)$ were treated as controls and were kept in the $15{ }^{\circ} \mathrm{C}$ chamber for the duration of the experiment. This allowed us to control for the effects of time in our study. These treatments are denoted as C-SM and C-WM to indicate their status as control groups. Additionally, at each temperature below $0{ }^{\circ} \mathrm{C}$, we moved three new bottles of SM $(N=47)$ and WM flies $(N=38)$ into the cold chamber, designated as "acute SM" and "acute WM", respectively. This allowed us to directly compare survival among flies in the gradual cooling treatment and flies similar to that used in our static susceptibility tests.

Survival was assessed daily by visual examination. Because chill coma occurred in the majority of flies below $0{ }^{\circ} \mathrm{C}$, particularly SM flies, a revival period was required at our lower temperatures in order to assess mortality. Below $0{ }^{\circ} \mathrm{C}$, the bottles were removed from the cold chamber daily and given 1-2 $\mathrm{h}$ to warm-up at $25^{\circ} \mathrm{C}$ prior to assessment. As chill coma recovery times increased with decreasing temperature, revival times were longest at our coldest temperatures.

Activity level was also recorded to determine how acclimation affects movement in D. suzukii. We used a 3-point scale and recorded the overall activity level of each treatment group daily, with three being the most activity, and 0 being the least. An activity score of three was assigned if the insects were actively flying within the bottles when they were removed from the cold chamber. A score of 2 indicated that they were walking, but not actively flying. A score of 1 indicated that they were standing, but not moving around the bottle. If touched with spatula, flies with a score of 1 would move aside. A score of 0 indicated chill coma. If touched with a spatula, the flies would fall over and remain unresponsive until they were revived after a period of time at $25^{\circ} \mathrm{C}$.

We measured pupal susceptibility in this experiment as well. Bottles of $<1$ day old non-acclimated pupae were held in the same cold chamber as the adults. After three days at each temperature, two bottles were removed and held at $25{ }^{\circ} \mathrm{C}$ for 7 days. Pupal survival was assessed using the same method previously described - we recorded the number of empty pupal cases, indicative of eclosion, the number of pupae that failed to eclose but displayed features consistent with advanced development, and the number of undeveloped pupae.

In all treatment bottles, accumulated condensation along the bottle walls was removed daily with a sterile wipe to prevent drowning. Throughout the course of the experiment, the flies were kept in rearing bottles (described previously), with $50 \mathrm{ml}$ of standard cornmeal-agar diet. The bottles were replaced once weekly, or as needed if the diet became sticky or wet with condensation. 


\subsection{Statistical Analysis}

Adult survival was assessed with generalizing estimating equations (GEE) modeling as the data were not independent at each time point [66]. GEE analysis was performed with the package geepack, using a binomial distribution (family $=$ binomial) and an independent correlation structure (corstr $=$ "independence"). The scale parameter was fixed at 1 , rather than estimated, because the data were binary (scale.fix $=\mathrm{T}$ ). We used a generalized linear model (GLM) with binomial distribution to assess the effects of temperature, duration of exposure, and acclimation treatment on survival and development ratios of pupal D. suzukii, followed by analysis of deviance.

We used GEE modeling for analysis of the dynamic acclimation data and determined the effects of treatment, temperature, and time on survival. Differences in survival between our four treatments: SM, C-SM, WM, and C-WM were compared with general linear hypothesis testing (GLHT) for posthoc multiple comparisons with Tukey contrasts, using the package multcomp. A separate GLM isolating treatment as a factor was used as the base model for our posthoc analyses.

A simple linear regression was used to predict activity level based on temperature. We compared activity level among our treatment groups with t-tests. Pupal survival and development following dynamic acclimation was assessed using a GLM with binomial distribution, followed by analysis of deviance and pairwise chi-squared tests for multiple comparisons of pupal survival. Analyses were performed in R i386 (version 3.4.0; the R Foundation for statistical computing (platform x86_64-w64-mingw32/x64); Vienna, Austria).

\section{Results}

\subsection{Adult Susceptibility}

We found that long-term developmental exposure to cool temperatures (WM flies) significantly improved survival in adult $D$. suzukii in response to acute and sustained cold exposure, compared to cold-acclimated and non-acclimated SM adults $\left(\chi^{2}=64.4, \mathrm{df}=2, p<0.001\right.$; Figure 3A-F). Temperature was a significant factor affecting survival $\left(\chi^{2}=241.5, \mathrm{df}=1, p<0.001\right)$, as well as the duration of exposure $\left(\chi^{2}=115.2, \mathrm{df}=1, p<0.001\right)$. At $4.4^{\circ} \mathrm{C}$ there was no difference between cold tolerant and cold-acclimated adults. However, at $1.67^{\circ} \mathrm{C}$ and below, there was a decline in survival compared to cold tolerant WM adults.

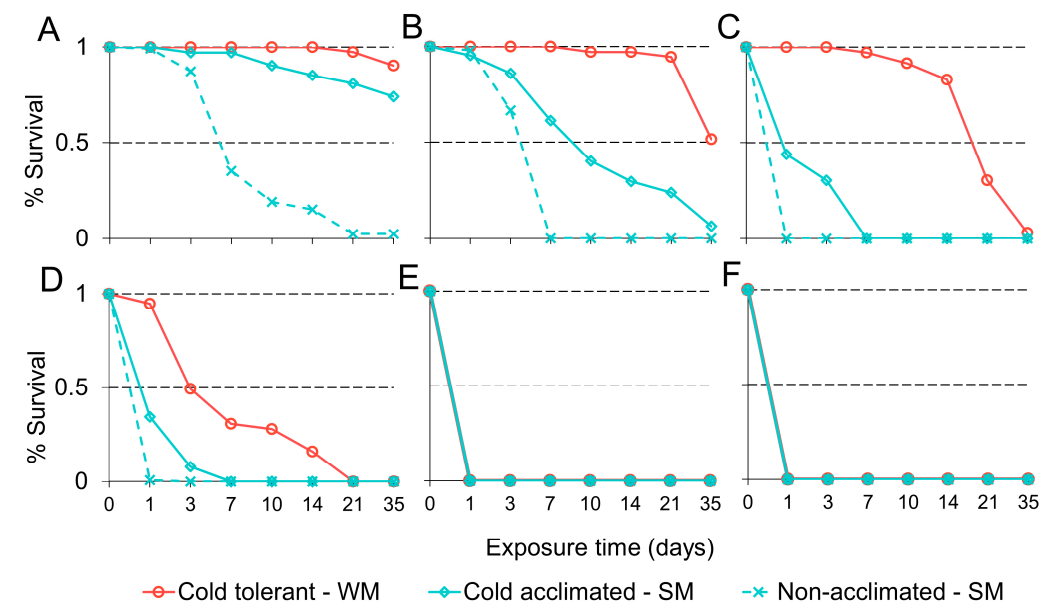

Figure 3. Mean percent survival (y-axis) of adult D. suzukii with varying states of cold hardiness in response to $4.4(\mathbf{A}), 1.67$ (B), -1.11 (C), -3.87 (D), $-6.67(\mathrm{E})$, or $-9.4{ }^{\circ} \mathrm{C}(\mathrm{F})$ chronic cold exposure for up to 35 days (x-axis). Line color indicates cold-hardiness treatment group: developmentally acclimated WM flies (solid red line), cold-acclimated SM flies (solid blue line), and non-acclimated SM flies (dashed blue line). 


\subsection{Pupal Susceptibility}

The baseline survival of our control flies (flies not subjected to a chill schedule) in the cold-acclimated and non-acclimated treatment groups was statistically different, with greater survival among non-acclimated pupae $\left(\chi^{2}=7.44, \mathrm{df}=1, p=0.006\right.$; Figure $\left.4 \mathrm{~A}\right)$. Among flies in our chill treatment groups, pupal survival was temperature dependent and decreased significantly with decreasing temperature $\left(\chi^{2}=256.46, \mathrm{df}=1,52, p<0.001\right.$; Figure 4B-F). Survival decreased with increasing duration of exposure $\left(\chi^{2}=237.8, \mathrm{df}=1,50, p<0.001\right)$. Overall, acclimation had a significant effect on survival, with greater survival among cold-acclimated pupae than non- acclimated pupae $\left(\chi^{2}=29.4\right.$, $\mathrm{df}=1,51, p<0.001$ ). No flies in the non-acclimated treatment survived below $0{ }^{\circ} \mathrm{C}$ after $24 \mathrm{~h}$ exposure. In contrast, we observed $4 \%$ survival among acclimated pupae after $72 \mathrm{~h}$ exposure to $-6.7^{\circ} \mathrm{C}$.
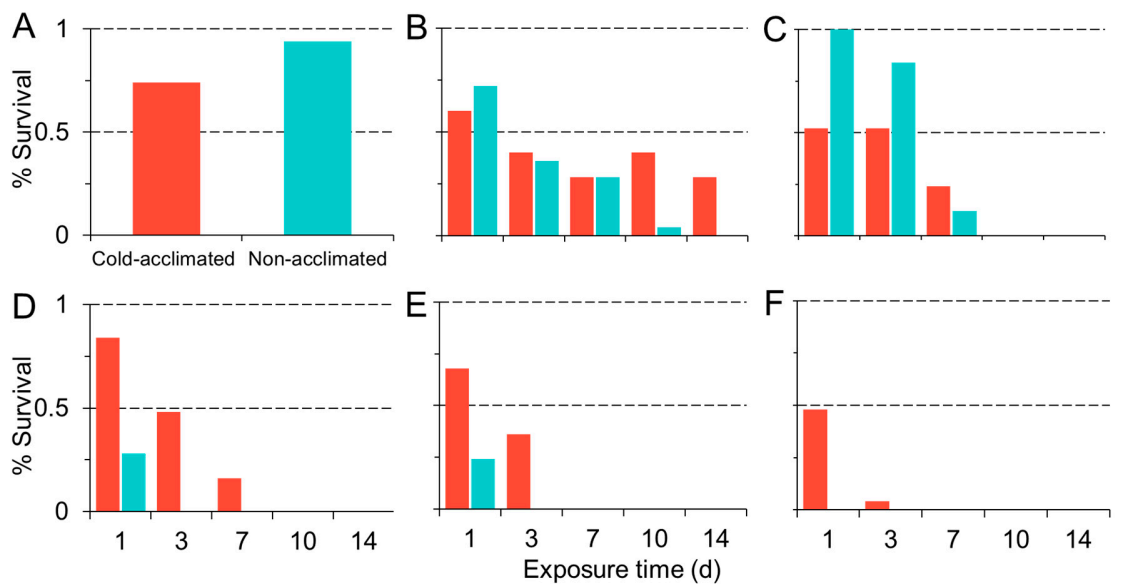

Cold-acclimated pupae

Non-acclimated pupae

Figure 4. Percent pupal survival (y-axis) of cold-acclimated (blue bars) and non-acclimated (red bars) D. suzukii held at 25 (A), 4.4 (B), $1.87\left(\right.$ C),$-1.11\left(\right.$ D),$-3.87\left(\right.$ E), and $-6.67{ }^{\circ} \mathrm{C}(\mathrm{F})$ for up to two weeks (x-axis).

We also observed a difference in development among acclimated and unacclimated pupae (Figure 5A-F). In addition to greater survival among acclimated pupae (Figure 5A,C,E), we also observed more complete development compared to unacclimated pupae (Figure 5B,D,F) $\left(\chi^{2}=90.68\right.$, $\mathrm{df}=1,28, p<0.001)$. Unacclimated pupae were more likely to lack late-stage developmental features such as wings, eyes, and legs, which are visible through the pupal casing. In acclimated flies we observed developed pupae at all temperatures at 7 days. At 10 days and 14 days, pupal development continued up to $-3.9^{\circ} \mathrm{C}$. In non-acclimated flies, comparatively, pupal development appeared to arrest below $4.4{ }^{\circ} \mathrm{C}$.

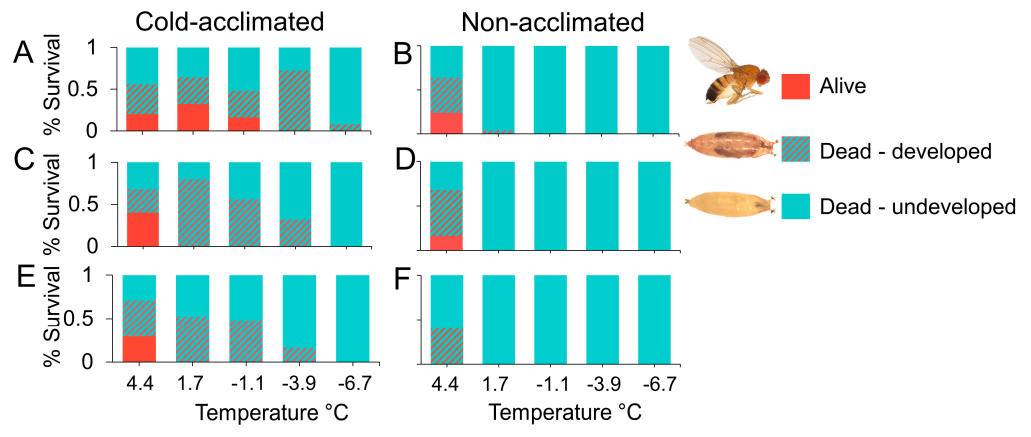

Figure 5. Percent survival and development of cold-acclimated (A, C, E) and non-acclimated (B, D, F) pupae exposed to low temperatures for 7 days (A-B), 10 days (C-D), or 14 days (E-F). Red bars indicate insects that eclosed during the observation period. 


\subsection{Dynamic Acclimation}

There was a significant effect of treatment on survival outcomes $\left(\chi^{2}=193, \mathrm{df}=3, p<0.001\right.$; Figure 6). WM flies survived in higher proportions than SM flies in both the experimental condition (gradual cooling) $(\mathrm{z}=21.66, p<0.001)$ and the control $(\mathrm{z}=8.56, p<0.001)$. Above $-5{ }^{\circ} \mathrm{C}$, WM flies survived as well as C-WM flies, which were held at $15^{\circ} \mathrm{C}$ for the duration of the study $(\mathrm{z}=0.99$, $0=0.75)$. Similarly, SM flies survived as well as C-SM flies above $-5{ }^{\circ} \mathrm{C}(\mathrm{z}=-0.19, p=1.00)$.

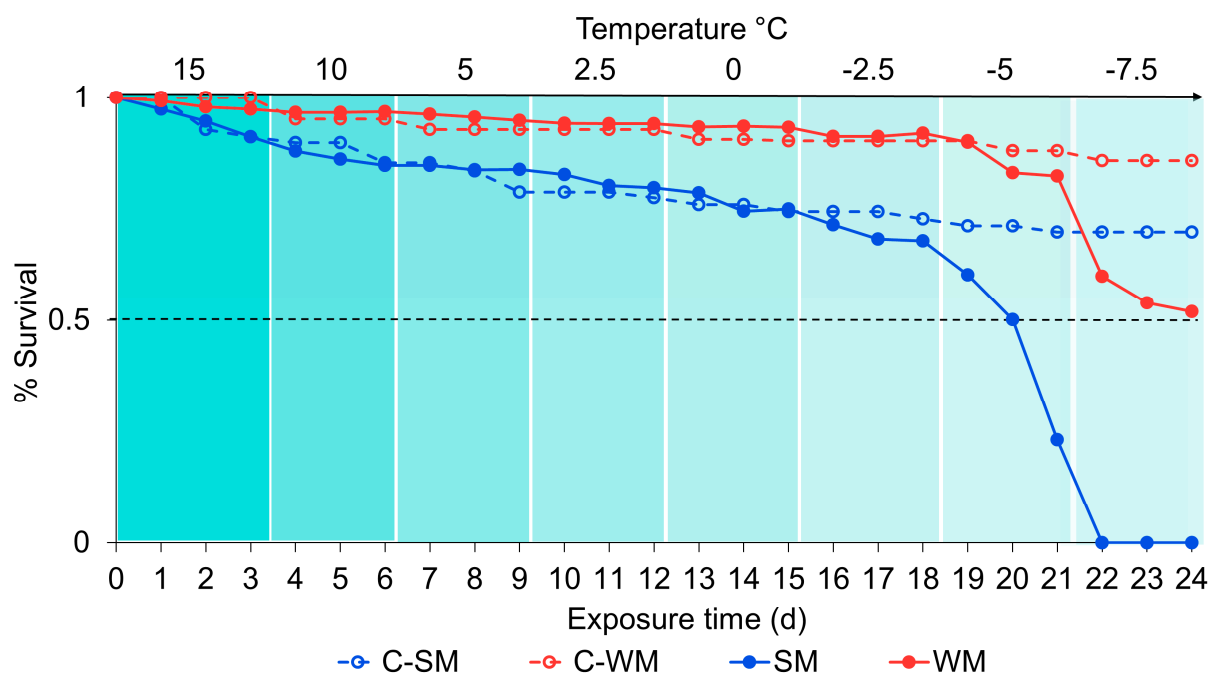

Figure 6. The effect of gradual cooling on mean survivorship in adult SM and WM D. suzukii. Survivorship was observed (y-axis) as the temperature (x-axis TOP) decreased over time (x-axis BOTTOM) in 3 days intervals. Color bands indicate differences in temperature, with lighter bands being cooler than darker bands. The solid dots and lines indicate percent survival per replicate among flies in the gradual cooling treatments (SM and WM). Open dots and dashed lines indicate flies in the control treatments (C-SM and C-WM) which were kept at $15^{\circ} \mathrm{C}$ for the duration of the study.

Temperature was also a significant factor $\left(\chi^{2}=312, \mathrm{df}=1, p<0.001\right)$. Survival remained high above $-5{ }^{\circ} \mathrm{C}$. After $72 \mathrm{~h}$ at $-5{ }^{\circ} \mathrm{C}$, the proportion of surviving SM flies declined from approximately $68 \%$ to $23 \%$. In contrast, there was only a $7 \%$ decline in survival among WM flies during this period. At $-7.5{ }^{\circ} \mathrm{C}$ no SM flies survived $24 \mathrm{~h}$ exposure. However, after $72 \mathrm{~h}$ exposure to $-7.5^{\circ} \mathrm{C}$, approximately $52 \% \mathrm{WM}$ flies survived. Of the surviving WM flies at the end of the experiment, 33\% were male and $67 \%$ were female.

Although time was a significant factor predicting survival outcomes $\left(\chi^{2}=155, \mathrm{df}=1, p<0.001\right)$, we decreased temperature over time making this is difficult to interpret. We did not observe a large decrease in survival over time among our control groups (C-SM and C-WM flies), which were not gradually cooled, but kept at $15{ }^{\circ} \mathrm{C}$ for the duration of the study to monitor baseline survival over time as the flies aged. Among C-SM flies, survival was approximately $70 \%$ after 24 days (the end of the study), and 86\% among C-WM flies. Survival in these groups gradually declined from the start of the experiment and survival among the experimental groups was similar to the controls up until day 19 , when the temperature was reduced to $-5^{\circ} \mathrm{C}$.

Below $0{ }^{\circ} \mathrm{C}$, we included two extra control groups to directly compare survival in our SM and WM groups with flies in an acute exposure scenario. Flies in the "acute SM" group were moved from the $25^{\circ} \mathrm{C}$ colony chamber to the cold chamber directly, while the "acute WM" group was moved from the $15^{\circ} \mathrm{C}$ chamber. The acute SM $(\mathrm{z}=10.04, p<0.001$; Figure 7A) and acute WM flies $(\mathrm{z}=4.3, p=0.0001$; Figure 7A) showed significantly greater mortality relative to the dynamic acclimation treatments. However, the acute WM flies survived in higher proportions than the SM flies following dynamic acclimation $(\mathrm{z}=-9.4, p<0.001)$. 

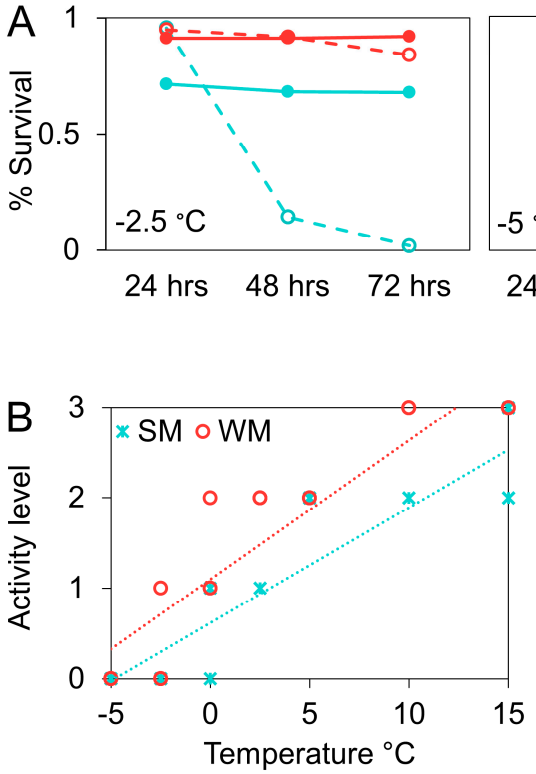
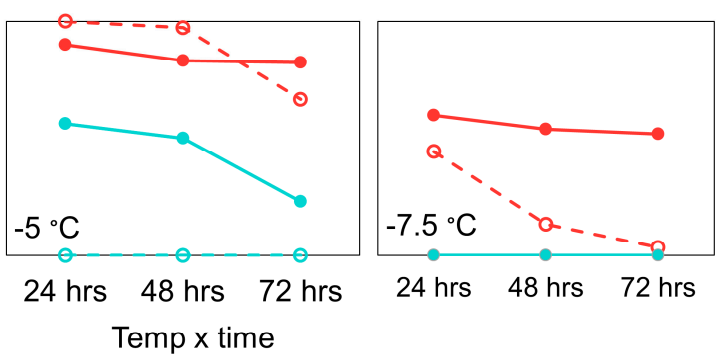

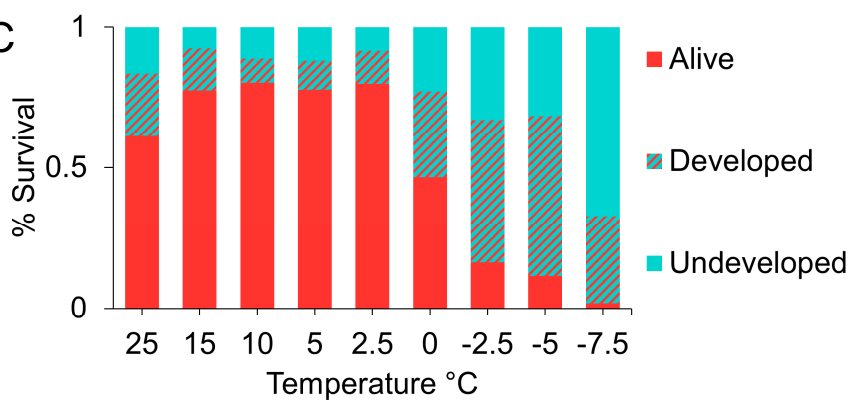

Figure 7. Mean percent survival at sub-freezing temperatures was compared among flies undergoing dynamic acclimation (SM and WM) with those acutely exposed (acute SM and acute WM) (A). The relationship between temperature and mean activity level in adult D. suzukii (B). Greater values indicate greater activity level. The dashed lines indicate best fit for SM (blue line) and WM (red line) flies. The effect of gradual cooling on pupal survival and development (C).

There was a positive relationship between activity level and temperature $(\mathrm{F}=215, \mathrm{df}=5,94$, $p<0.001$; Figure 7B). We observed complete chill coma below $0{ }^{\circ} \mathrm{C}$ in SM flies and $-2.5^{\circ} \mathrm{C}$ in $\mathrm{WM}$ flies. Flies in the thermal control treatments (C-SM and C-WM flies) displayed constant activity levels throughout the course of the experiment, indicating that time/age did not affect activity level. C-WM flies were consistently more active at $15{ }^{\circ} \mathrm{C}$ than C-SM flies $(\mathrm{t}=4.25, p<0.001)$.

Survival among pupae was temperature dependent $\left(\chi^{2}=211.7, \mathrm{df}=1,7, p<0.001\right.$; Figure 7C). Near freezing, from $2.5^{\circ} \mathrm{C}$ to $0{ }^{\circ} \mathrm{C}$, there was a significant decline in survival from approximately $80 \%$ to $47 \%\left(\chi^{2}=42.56, \mathrm{df}=1, p<0.001\right)$. There was another sharp decrease in survival when the temperature was reduced to $-2.5^{\circ} \mathrm{C}\left(\chi^{2}=38.75, \mathrm{df}=1, p<0.001\right)$. Between $-2.5{ }^{\circ} \mathrm{C}$ and $-5{ }^{\circ} \mathrm{C}$ survival was similar, around $15 \%\left(\chi^{2}=1.51, \mathrm{df}=1, p=0.23\right)$. We observed $1 \%$ survival at the lowest temperature we tested, $-7.5^{\circ} \mathrm{C}\left(\chi^{2}=8.89, \mathrm{df}=1, p=0.003\right)$.

\section{Discussion}

The physiological degree of cold hardening in D. suzukii is likely dependent on the acclimation temperature to which the insects are exposed during larval and early adult development. The current study investigated the comparative survival of $D$. suzukii after static and dynamic acclimation protocols in adult and pupal flies and demonstrated that gradual reductions in temperature were associated with greater survival outcomes among SM and WM flies, than static acclimation protocols in which a single temperature was employed. Our study suggests that the thermal limits of survival in D. suzukii ought not to be defined by one value. Rather, thermal susceptibility likely varies with lifestage and experience, and as such, there may be variable $\mathrm{LT}^{50}$ values for this species depending on those factors. Cold hardening and the capacity for overwintering survival may be profoundly affected by how rapidly cooling occurs, and gradual cooling may increase cold tolerance in this species. More research is needed to determine the role of fluctuating daily temperatures in the physiogenesis of cold tolerance in D. suzukii, as it is unclear what effect thermal instability may have on survival outcomes. It also unclear whether thermal susceptibility is similarly affected by gradual warming, thereby extending the limits of survival in warmer climates. 
In the first two experiments, we compared survival among acclimated and non-acclimated flies using a static acclimation protocol. Developmentally acclimated WM flies survived the best at cold temperatures, followed by cold-acclimated SM flies. Non-acclimated SM flies did not survive prolonged exposure to temperatures below $4.4^{\circ} \mathrm{C}$. Below freezing, all non-acclimated flies died within $24 \mathrm{~h}$. These data are consistent with previous reports of varying levels of cold hardiness in adult D. suzukii $[20,22,29,32,33,67]$. At least some of the physiological changes associated with short-term adult cold acclimation appear to occur rapidly in Drosophilids. In D. melanogaster, short-term adult acclimation is sufficient to induce a $22 \%$ increase in cold tolerance [38]. We found similar effects in D. suzukii, where short-term acclimation was sufficient to induce moderate protection. Cold-acclimated SM flies survived longer than non-acclimated flies above $-5^{\circ} \mathrm{C}$. However, WM flies, which developed under cool conditions, were much more robust and survived the longest.

We observed similar results when we manipulated cold hardiness in pupal D. suzukii. Acquired cold hardiness improved the survival of pupal D. suzukii after chronic exposure to cold temperatures. Acclimated pupae survived up to a week at just above and below freezing, indicating greater cold tolerance than was previously identified $[22,31,37,45]$. This effect was most pronounced after $24 \mathrm{~h}$ exposure when the survival of acclimated pupae became greater than survival among non-acclimated insects. Greater initial survival among non-acclimated flies in our control groups, which were allowed to eclose without cold exposure, indicates that acclimation may be a stressor that results in death among some developing flies. This is consistent with previous reports of high juvenile mortality at low temperatures [45]. However, we observed that among the pupae that failed to eclose, those that were previously acclimated showed more advanced development than non-acclimated flies. In non-acclimated flies, pupal development appeared to arrest below $4.4^{\circ} \mathrm{C}$, whereas acclimated pupae showed nearly complete development, with visible body structures such as wings, legs, and eyes at temperatures as low as $-3.5^{\circ} \mathrm{C}$. Although we did not directly compare juvenile and adult cold susceptibilities, we did note the comparative survival among acclimated and non-acclimated insects at these two life stages. Juveniles were susceptible to freezing temperatures below $-5{ }^{\circ} \mathrm{C}$, but so were adult flies in their respective assays. Both groups showed consistent survival above $-5^{\circ} \mathrm{C}$ and the patterns for survival were more similar than we expected. This is surprising given that juvenile susceptibility is common among drosophilids [43]. While our data suggest that pupae are more cold tolerant than previously observed, extended periods at or below freezing appear fatal, indicating that juvenile overwintering diapause is unlikely.

In the final experiment, we re-assessed survival following dynamic acclimation, or a slow progression toward freezing temperatures. We compared SM and WM fly survival daily and found improved survival outcomes among both groups. While WM survival was greater than SM survival throughout the study, there was not a significant decline in survival among SM flies until the temperature was reduced to $-5{ }^{\circ} \mathrm{C}$. In contrast, our initial tests using static acclimation suggested SM flies were susceptible at $-1.87^{\circ} \mathrm{C}$. Above $-5^{\circ} \mathrm{C}$, survival followed a pattern of gradual and mild decline consistent with our control flies, which were held at $15^{\circ} \mathrm{C}$ for the duration of the study. Among those flies too, WM survival was greater than SM survival. The thermal limit for WM flies was lower than SM flies, and did not start to decline until temperatures were reduced even further, to $-7.5^{\circ} \mathrm{C}$. While all flies in the SM treatment were dead within $1 \mathrm{~d}$ at $-7.5^{\circ} \mathrm{C}$, approximately $50 \%$ of our WM flies were still alive after 3 days. This is a dramatic increase in survival compared to our initial thermal susceptibility assessments, which suggested a lower lethal limit of $-6.7^{\circ} \mathrm{C}$. Similarly, pupal survival improved following gradual cooling. Although survival at temperatures below freezing was low, we did observe some level of survival at all of our tested temperatures, indicating greater cold tolerance than previously demonstrated.

Gradual cooling is likely a better reflection of the cold hardening D. suzukii would experience in nature [50], and appears to confer greater protection against low temperatures than static acclimation [68,69]. The internal physiogenesis that occurs during cold hardening is likely an ongoing, dynamic process proportional to the degree of cold to which the insects are exposed [55]. 
As temperatures decrease in the late fall and early winter, local populations of $D$. suzukii may become increasingly adapted to the cool weather as physiological changes, such as increases in carbohydrate stores develop $[30,32,41]$. In D. melanogaster, gradual acclimation, like developmental acclimation, appears to involve long-lasting physiological changes in gene expression, thereby promoting cold hardiness [41,68]. Indeed, our data suggest that SM flies may be moderately cold hardened without displaying the external phenotypic traits associated with WM flies. In this species we should perhaps distinguish between the morphogenesis associated with external WM traits and the physiogenesis that may occur in both WM and SM flies [55].

In addition to physiological adaptations via variation in phenotypic expression, it is likely that D. suzukii uses behavioral and environmental strategies to thermo-modulate. The Japanese Drosophilid, D. curviceps, is known to thermo-modulate via seasonal migration between the warmer lowlands and the cooler highlands [70]. Similar migration could occur in D. suzukii allowing it to avoid the most extreme low temperatures in a given area. Indeed, there is evidence that $D$. suzukii moves between crop land and adjacent wooded areas during peak field season [71-75]. Similarly, there is reason to believe that these insects may overwinter in habitats such as leaf litter $[20,25,76]$, which provides thermal insulation and keeps ground temperatures within a few degrees of freezing throughout the winter $[59,77,78]$. In the bertha armyworm, Mamestra configurata (Lepidoptera: Noctuidae), and the rice water weevil, Lissorhoptrus oryzophilus (Coleoptera: Curculionidae), survival of overwintering immatures is greatest in areas of deep snow pack $[79,80]$. Similarly, D. suzukii may access insulation in the top soil layers, during periods of heavy snow and extreme cold, such that the temperature is relatively stable at $0{ }^{\circ} \mathrm{C}$. This freeze-avoidant strategy may allow WM D. suzukii to successfully overwinter by avoiding incompatibly low temperatures.

\section{Conclusions}

Given the economic impact D. suzukii has had in temperate growing regions, these data may have important implications for offseason population monitoring and management. Future research ought to identify overwintering hot-spots that occur near agricultural zones, track migration during late fall and early spring, and look for novel methods of population suppression that exploit the ecological niche this insect inhabits. There are concerns that D. suzukii may utilize urban refugia [11,14,20-22,81], which may provide access to heat and food and therefore serve as a population reservoir. These environments should be studied closely to determine if there is an opportunity to reduce overwintering success in this invasive, economically destructive species.

Increased globalization has resulted in the frequent invasion of non-native pest species, such as D. suzukii into foreign environments. In addition, climate change is associated with marked range expansion of pests into previously uninhabitable climates closer to the poles $[59,63]$. While predictive models $[4,63]$ have suggested that $D$. suzukii movement may be limited by narrow thermal thresholds between approximately $10-30{ }^{\circ} \mathrm{C}[23,82]$, our data suggests that such models may benefit from taking dynamic acclimation, and the plasiticity of the cold hardening response in D. suzukii, into account. The ability to adaptively cope with thermal extremes may be a previously unrecognized risk factor for expanding latitudinal invasion [63] and new continental invasion events by D. suzukii [4].

Author Contributions: Conceptualization, D.S., A.W., and G.L.; Methodology, D.S. and G.L.; Formal Analysis, D.S.; Investigation, D.S.; Resources, G.L.; Writing-Original Draft Preparation, D.S.; Writing-Review \& Editing, D.S., G.L., A.W.; Supervision, G.L.; Funding Acquisition, G.L.

Funding: This research was funded by USDA-NIFA Specialty Crop Research Initiative grant No. 2016-0228-08.

Acknowledgments: Special thanks to Steven Hesler, Karen Wentworth, Gabrielle Brind-Amour, Molly Cappiello, Mason Clark, Shin-young Cha and Rachael Brown for their technical assistance with this project.

Conflicts of Interest: The authors declare no conflict of interest. 


\section{References}

1. Cini, A.; Ioriatti, C.; Anfora, G. A review of the invasion of Drosophila suzukii in Europe and a draft research agenda for integrated pest management. Bull. Insectol. 2012, 65, 149-160.

2. Asplen, M.K.; Anfora, G.; Biondi, A.; Choi, D.-S.; Chu, D.; Daane, K.M.; Gibert, P.; Gutierrez, A.P.; Hoelmer, K.A.; Hutchison, W.D.; et al. Invasion biology of spotted wing Drosophila (Drosophila suzukii): A global persepcetive and future priorities. J. Pest Sci. 2015, 88, 469-494. [CrossRef]

3. Deprá, M.; Poppe, J.L.; Schmitz, H.J.; De Toni, D.C.; Valente, V.L.S. The first records of the invasive pest Drosophila suzukii in the South American continent. J. Pest Sci. 2014, 87, 379-383. [CrossRef]

4. dos Santos, L.A.; Mendes, M.F.; Krüger, A.P.; Blauth, M.L.; Gottschalk, M.S.; Garcia, F.R.M.; Alvarez, E.; Jara, C.; Godoy-Herrera, R.; Yemshanov, D. Global potential distribution of Drosophila suzukii (Diptera, Drosophilidae). PLoS ONE 2017, 12, e0174318. [CrossRef] [PubMed]

5. Kanzawa, T. Studies on Drosophila suzukii Mats. Yamanashi Kofu Agric. Exp. Stn. 1939, $29,49$.

6. Rota-Stabelli, O.; Blaxter, M.; Anfora, G. Drosophila suzukii. Curr. Biol. 2013, 23, R8-R9. [CrossRef] [PubMed]

7. Atallah, J.; Teixeira, L.; Salazar, R.; Zaragoza, G.; Kopp, A. The making of a pest: The evolution of a fruit-penetrating ovipositor in Drosophila suzukii and related species. Proc. R. Soc. Lond. B Biol. Sci. 2014, 281. [CrossRef] [PubMed]

8. Karageorgi, M.; Bräcker, L.B.; Lebreton, S.; Minervino, C.; Cavey, M.; Siju, K.P.; Grunwald Kadow, I.C.; Gompel, N.; Prud'homme, B. Evolution of Multiple Sensory Systems Drives Novel Egg-Laying Behavior in the Fruit Pest Drosophila suzukii. Curr. Biol. 2017, 27, 847-853. [CrossRef] [PubMed]

9. Bolda, M.P.; Goodhue, R.E.; Zalom, F.G. Spotted Wing Drosophila: Potential Economic Impact of a Newly Established Pest. Updat. Univ. Calif. Giannini Found. Agric. Econ. 2010, 13, 5-8.

10. Walsh, D.B.; Bolda, M.P.; Goodhue, R.E.; Dreves, A.J.; Lee, J.; Bruck, D.J.; Walton, V.M.; O’Neal, S.D.; Zalom, F.G. Drosophila suzukii (Diptera: Drosophilidae): Invasive Pest of Ripening Soft Fruit Expanding its Geographic Range and Damage Potential. J. Integr. Pest Manag. 2011, 2, G1-G7. [CrossRef]

11. Hamby, K.A.; Bellamy, D.E.; Chiu, J.C.; Lee, J.C.; Walton, V.M.; Wiman, N.G.; York, R.M.; Biondi, A. Biotic and abiotic factors impacting development, behavior, phenology, and reproductive biology of Drosophila suzukii. J. Pest Sci. 2016, 89, 605-619. [CrossRef]

12. Wiman, N.G.; Walton, V.M.; Dalton, D.T.; Anfora, G.; Burrack, H.J.; Chiu, J.C.; Daane, K.M.; Grassi, A.; Miller, B.; Tochen, S.; et al. Integrating Temperature-Dependent Life Table Data into a Matrix Projection Model for Drosophila suzukii Population Estimation. PLoS ONE 2014, 9, e106909. [CrossRef] [PubMed]

13. Elsensohn, J.E.; Loeb, G.M. Non-crop host sampling yields insights into small-scale population dynamics of Drosophila suzukii (Matsumura). Insects 2018, 9. [CrossRef] [PubMed]

14. Rossi-Stacconi, M.V.; Kaur, R.; Mazzoni, V.; Ometto, L.; Grassi, A.; Gottardello, A.; Rota-Stabelli, O.; Anfora, G. Multiple lines of evidence for reproductive winter diapause in the invasive pest Drosophila suzukii: Useful clues for control strategies. J. Pest Sci. 2016, 89, 689-700. [CrossRef]

15. Thistlewood, H.M.A.; Gill, P.; Beers, E.H.; Shearer, P.W.; Walsh, D.B.; Rozema, B.M.; Acheampong, S.; Castagnoli, S.; Yee, W.L.; Smytheman, P.; et al. Spatial Analysis of Seasonal Dynamics and Overwintering of Drosophila suzukii (Diptera: Drosophilidae) in the Okanagan-Columbia Basin, 2010-2014. Environ. Entomol. 2018, 47, 221-232. [CrossRef] [PubMed]

16. Inoue, Y.; Tobari, Y.N.; Tsuno, K.; Watanabe, T.K. Association of chromosome and enzyme polymorphisms in natural and cage populations of Drosophila melanogaster. Genetics 1984, 106, 267-277. [PubMed]

17. Machado, H.E.; Bergland, A.O.; O’Brien, K.R.; Behrman, E.L.; Schmidt, P.S.; Petrov, D.A. Comparative population genomics of latitudinal variation in Drosophila simulans and Drosophila melanogaster. Mol. Ecol. 2016, 25, 723-740. [CrossRef] [PubMed]

18. Mukai, T.; Yamaguchi, O. The genetic structure of natural populations of Drosophila melanogaster. XI. Genetic variability in a local population. Genetics 1974, 76, 339-366. [PubMed]

19. Fabian, D.K.; Kapun, M.; Nolte, V.; Kofler, R.; Schmidt, P.S.; Schlötterer, C.; Flatt, T. Genome-wide patterns of latitudinal differentiation among populations of Drosophila melanogaster from North America. Mol. Ecol. 2012, 21, 4748-4769. [CrossRef] [PubMed]

20. Jakobs, R.; Gariepy, T.D.; Sinclair, B.J. Adult plasticity of cold tolerance in a continental-temperate population of Drosophila suzukii. J. Insect Physiol. 2015, 79, 1-9. [CrossRef] [PubMed] 
21. Kimura, M.T. Cold and heat tolerance of drosophilid flies with reference to their latitudinal distributions. Oecologia 2004, 140, 442-449. [CrossRef] [PubMed]

22. Dalton, D.T.; Walton, V.M.; Shearer, P.W.; Walsh, D.B.; Caprile, J.; Isaacs, R. Laboratory survival of Drosophila suzukii under simulated winter conditions of the Pacific Northwest and seasonal field trapping in five primary regions of small and stone fruit production in the United States. Pest Manag. Sci. 2011, 67, 1368-1374. [CrossRef] [PubMed]

23. Tochen, S.; Dalton, D.T.; Wiman, N.; Hamm, C.; Shearer, P.W.; Walton, V.M. Temperature-Related Development and Population Parameters for Drosophila suzukii (Diptera: Drosophilidae) on Cherry and Blueberry. Environ. Entomol. 2014, 43, 501-510. [CrossRef] [PubMed]

24. Zerulla, F.N.; Schmidt, S.; Streitberger, M.; Zebitz, C.P.W.; Zelger, R. On the overwintering ability of Drosophila suzukii in South Tyrol. J. Berry Res. 2015, 5, 41-48. [CrossRef]

25. Wallingford, A.K.; Lee, J.C.; Loeb, G.M. The influence of temperature and photoperiod on the reproductive diapause and cold tolerance of spotted-wing drosophila, Drosophila suzukii. Entomol. Exp. Appl. 2016, 159, 327-337. [CrossRef]

26. Grassi, A.; Gottardello, A.; Dalton, D.T.; Tait, G.; Rendon, D.; Ioriatti, C.; Gibeaut, D.; Rossi Stacconi, M.V.; Walton, V.M. Seasonal Reproductive Biology of Drosophila suzukii (Diptera: Drosophilidae) in Temperate Climates. Environ. Entomol. 2018, 47, 166-174. [CrossRef] [PubMed]

27. Gibert, P.; Moreteau, B.; David, J.R. Developmental constraints on an adaptive plasticity: Reaction norms of pigmentation in adult segments of Drosophila melanogaster. Evol. Dev. 2000, 2, 249-260. [CrossRef] [PubMed]

28. David, J.; Moreteau, B.; Gauthier, J.; Pétavy, G.; Stockel, A.; Imasheva, A. Reaction norms of size characters in relation to growth temperature in Drosophila melanogaster: An isofemale lines analysis. Genet. Sel. Evol. 1994, 26, 229-251. [CrossRef]

29. Hoffmann, A.A.; Sorensen, J.G.; Loeschchke, V. Adaptation of Drosophila to temperature extremes: Bringing together quantitative and molecular approaches. J. Therm. Biol. 2003, 28, 175-216. [CrossRef]

30. Overgaard, J.; Malmendal, A.; Sørensen, J.G.; Bundy, J.G.; Loeschcke, V.; Chr Nielsen, N.; Holmstrup, M. Metabolomic profiling of rapid cold hardening and cold shock in Drosophila melanogaster. J. Insect Physiol. 2007, 53, 1218-1232. [CrossRef] [PubMed]

31. Stephens, A.R.; Asplen, M.K.; Hutchison, W.D.; Venette, R.C. Cold Hardiness of Winter-Acclimated Drosophila suzukii (Diptera: Drosophilidae) Adults. Environ. Entomol. 2015, 44, 1619-1626. [CrossRef] [PubMed]

32. Shearer, P.W.; West, J.D.; Walton, V.M.; Brown, P.H.; Svetec, N.; Chiu, J.C. Seasonal cues induce phenotypic plasticity of Drosophila suzukii to enhance winter survival. BMC Ecol. 2016, 16. [CrossRef] [PubMed]

33. Wallingford, A.K.; Loeb, G.M. Developmental Acclimation of Drosophila suzukii (Diptera: Drosophilidae) and Its Effect on Diapause and Winter Stress Tolerance. Environ. Entomol. 2016, 45, 1081-1089. [CrossRef] [PubMed]

34. Toxopeus, J.; Jakobs, R.; Ferguson, L.V.; Gariepy, T.D.; Sinclair, B.J. Reproductive arrest and stress resistance in winter-acclimated Drosophila suzukii. J. Insect Physiol. 2016, 89, 37-51. [CrossRef] [PubMed]

35. Tonina, L.; Mori, N.; Giomi, F.; Battisti, A. Development of Drosophila suzukii at low temperatures in mountain areas. J. Pest Sci. 2016, 89, 667-678. [CrossRef]

36. Tucic, N. Genetic capacity for adaptation to cold resistance at different developmental stages of Drosophila melanogaster. Evolution (N. Y.) 1979, 33, 3-358. [CrossRef]

37. Kimura, M.T. Adaptations to temperate climates and evolution of overwintering strategies in the Drosophila melanogaster species group. Evolution (N. Y.) 1988, 42, 1288-1297.

38. Chen, C.; Walker, V. Increase in cold-shock tolerance by selection of cold resistant lines in Drosophila melanogaster. Ecol. Entomol. 1993, 18, 184-190. [CrossRef]

39. Ohtsu, T.; Kimura, M.T.; Hori, S.H. The influence of eclosion timing on winter survival and triacylglycerol accumulation in four temperate species of Drosophila. Physiol. Entomol. 1995, 20, 248-252. [CrossRef]

40. Lee, R.E. Principles of Insect Low Temperature Tolerance. In Insects at Low Temperature; Springer: Boston, MA, USA, 1991; pp. 17-46.

41. Kelty, J.D.; Lee, R.E., Jr. Rapid cold-hardening of Drosophila melanogaster (Diptera: Drosophilidae) during ecologically based thermoperiodic cycles. J. Exp. Biol. 2001, 204, 1659-1666. [PubMed]

42. Denlinger, D.L.; Lee, R.E. Low Temperature Biology of Insects, 1st ed.; Cambridge University Press: New York, NY, USA, 2010; ISBN 978-0-521-88635-2. 
43. Strachan, L.A.; Tarnowski-Garner, H.E.; Marshall, K.E.; Sinclair, B.J. The evolution of cold tolerance in Drosophila larvae. Physiol. Biochem. Zool. 2011, 84, 43-53. [CrossRef] [PubMed]

44. Sinclair, B.J. Insect cold tolerance: How many kinds of frozen? Eur. J. Entomol. 1999, 96, 157-164.

45. Aly, M.F.K.; Kraus, D.A.; Burrack, H.J. Effects of Postharvest Cold Storage on the Development and Survival of Immature Drosophila suzukii (Diptera: Drosophilidae) in Artificial Diet and Fruit. J. Econ. Entomol. 2016, 147, tow289. [CrossRef] [PubMed]

46. Enriquez, T.; Colinet, H. Basal tolerance to heat and cold exposure of the spotted wing drosophila, Drosophila suzukii. PeerJ 2017, 5, e3112. [CrossRef] [PubMed]

47. Lankinen, P.; Riihimaa, A.J. Weak circadian eclosion rhythmicity in Chymomyza costata (Diptera: Drosophilidae), and its independence of diapause type. J. Insect Physiol. 1992, 38, 803-811. [CrossRef]

48. Kostal, V.; Berkova, P.; Simek, P. Remodelling of membrane phospholipids during transition to diapause and cold-acclimation in the larvae of Chymomyza costata (Drosophilidae). Comp. Biochem. Physiol. Part B 2003, 135, 407-419. [CrossRef]

49. Shimada, K.; Riihimaa, A. Cold acclimation, inoculative freezing and slow cooling: Essential factors contributing to the freezing-tolerance in diapausing larvae of Chymomyza costata (Diptera: Drosophilidae). Cryo-Letters 1988, 9, 5-10.

50. Kellermann, V.; Loeschcke, V.; Hoffmann, A.A.; Kristensen, T.N.; Fløjgaard, C.; David, J.R.; Svenning, J.-C.; Overgaard, J. Phylogenetic constraints in key functional traits behind species' climate niches: Patterns of desiccation and cold resistance across 95 Drosophila species. Evolution (N. Y.) 2012, 66, 3377-3389. [CrossRef]

51. Hori, Y.; Kimura, A.T. Relationship between Cold Stupor and Cold Tolerance in Drosophila (Diptera: Drosophilidae). Physiol. Chem. Ecol. 1998, 27, 1297-1302. [CrossRef]

52. Hoffmann, A.A.; Shirriffs, J.; Scott, M. Relative importance of plastic vs genetic factors in adaptive differentiation: Geographical variation for stress resistance in Drosophila melanogaster from eastern Australia. Funct. Ecol. 2005, 19, 222-227. [CrossRef]

53. Everatt, M.J.; Bale, J.S.; Convey, P.; Worland, M.R.; Hayward, S.A.L. The effect of acclimation temperature on thermal activity thresholds in polar terrestrial invertebrates. J. Insect Physiol. 2013, 59, 1057-1064. [CrossRef] [PubMed]

54. Kostal, V. Eco-physiological phases of insect diapause. J. Insect Physiol. 2006, 52, 113-127. [CrossRef] [PubMed]

55. Andrewartha, H.G. Diapause in relation to the ecology of insects. Biol. Rev. 1952, 27, 50-107. [CrossRef]

56. Andersen, J.L.; Manenti, T.; Sørensen, J.G.; MacMillan, H.A.; Loeschcke, V.; Overgaard, J. How to assess Drosophila cold tolerance: Chill coma temperature and lower lethal temperature are the best predictors of cold distribution limits. Funct. Ecol. 2015, 29, 55-65. [CrossRef]

57. Jensen, D.; Overgaard, J.; Sorensen, J.G. The influence of developmental stage on cold shock resistance and ability to cold-harden in Drosophila melanogaster. J. Insect Physiol. 2007, 53, 179-186. [CrossRef] [PubMed]

58. Overgaard, J.; Kristensen, T.N.; Mitchell, K.A.; Hoffmann, A.A. Thermal tolerance in widespread and tropical Drosophila species: Does phenotypic plasticity increase with latitude? Am. Nat. 2011, 178 (Suppl. 1), S80-S96. [CrossRef]

59. Bale, J.S.; Hayward, S.A.L. Insect overwintering in a changing climate. J. Exp. Biol. 2010, 213, 980-994. [CrossRef] [PubMed]

60. Bale, J.S.; Masters, G.J.; Hodkinson, I.D.; Awmack, C.; Bezemer, T.M.; Brown, V.K.; Butterfield, J.; Buse, A.; Coulson, J.C.; Farrar, J.; et al. Herbivory in global climate change research: Direct effects of rising temperature on insect herbivores. Glob. Chang. Biol. 2002, 8, 1-16. [CrossRef]

61. Rosenzweig, C.; Iglesius, A.; Yang, X.B.; Epstein, P.R.; Chivian, E. Climate change and extreme weather events-Implications for food production, plant diseases, and pests. Glob. Chang. Hum. Heal. 2001, 2, 90-104. [CrossRef]

62. Pecl, G.T.; Araújo, M.B.; Bell, J.D.; Blanchard, J.; Bonebrake, T.C.; Chen, I.-C.; Clark, T.D.; Colwell, R.K.; Danielsen, F.; Evengård, B.; et al. Biodiversity redistribution under climate change: Impacts on ecosystems and human well-being. Science 2017, 355. [CrossRef] [PubMed]

63. Langille, A.B.; Arteca, E.M.; Newman, J.A. The impacts of climate change on the abundance and distribution of the Spotted Wing Drosophila (Drosophila suzukii) in the United States and Canada. PeerJ 2017, 5, e3192. [CrossRef] [PubMed] 
64. Wallingford, A.K.; Hesler, S.P.; Cha, D.H.; Loeb, G.M. Behavioral response of spotted-wing drosophila, Drosophila suzukii Matsumura, to aversive odors and a potential oviposition deterrent in the field. Pest Manag. Sci. 2016, 72, 701-706. [CrossRef] [PubMed]

65. David, J.R.; Gibert, P.; Moreteau, B.; Gilchrist, G.W.; Huey, R.B. The fly that came in from the cold: Geographic variation of recovery time from low-temperature exposure in Drosophila subobscura. Funct. Ecol. 2003, 17, 425-430. [CrossRef]

66. Hanley, J.A.; Negassa, A.; Forrester, J.E. Statistical Analysis of Correlated Data Using Generalized Estimating Equations: An Orientation. Am. J. Epidemiol. 2003, 157, 364-375. [CrossRef] [PubMed]

67. Plantamp, C.; Salort, K.; Gibert, P.; Dumet, A.; Mialdea, G.; Mondy, N.; Voituron, Y. All or nothing: Survival, reproduction and oxidative balance in Spotted Wing Drosophila (Drosophila suzukii) in response to cold. J. Insect Physiol. 2016, 89, 28-36. [CrossRef] [PubMed]

68. Colinet, H.; Hoffmann, A.A. Comparing phenotypic effects and molecular correlates of developmental, gradual and rapid cold acclimation responses in Drosophila melanogaster. Funct. Ecol. 2012, 26, 84-93. [CrossRef]

69. Rako, L.; Hoffmann, A.A. Complexity of the cold acclimation response in Drosophila melanogaster. J. Insect Physiol. 2006, 52, 94-104. [CrossRef] [PubMed]

70. Kimura, M.T.; Beppu, K. Climatic adaptations in the Drosophila immigrans species group: Seasonal migration and thermal tolerance. Ecol. Entomol. 1993, 18, 141-149. [CrossRef]

71. Klick, J.; Yang, W.Q.; Walton, V.M.; Dalton, D.T.; Hagler, J.R.; Dreves, A.J.; Lee, J.C.; Bruck, D.J. Distribution and activity of Drosophila suzukii in cultivated raspberry and surrounding vegetation. J. Appl. Entomol. 2016, 140, 37-46. [CrossRef]

72. Diepenbrock, L.M.; Swoboda-Bhattarai, K.A.; Burrack, H.J. Ovipositional preference, fidelity, and fitness of Drosophila suzukii in a co-occurring crop and non-crop host system. J. Pest Sci. 2016, 89, 761-769. [CrossRef]

73. Iglesias, L.E.; Liburd, O.E. The effect of border sprays and between-row soil tillage on Drosophila suzukii in organic blackberry production. J. Appl. Entomol. 2017, 141, 19-27. [CrossRef]

74. Liburd, O.E.; Iglesias, L.E.; Nyoike, T.W. Integrated pest management strategies to combat the invasive spotted wing drosophila: Drosophila suzukii (Matsumura) Diptera: Drosophilidae. In Proceedings of the NABREW Conference, Atlantic City, NJ, USA, 24 June 2014. [CrossRef]

75. Pelton, E.; Gratton, C.; Isaacs, R.; Van Timmeren, S.; Blanton, A.; Guédot, C. Earlier activity of Drosophila suzukii in high woodland landscapes but relative abundance is unaffected. J. Pest Sci. 2016, 89, 725-733. [CrossRef]

76. Hoffmann, A.A.; Scott, M.; Partridge, L.; Hallas, R. Overwintering in Drosophila melanogaster: Outdoor field cage experiments on clinal and laboratory selected populations help to elucidate traits under selection. J. Evol. Biol. 2003, 16, 614-623. [CrossRef] [PubMed]

77. Leather, S.R.; Walters, K.F.A.; Bale, J.S. The Ecology of Insect Overwintering, 1st ed.; Cambridge University Press: New York, NY, USA, 1993.

78. Mukerji, M.K.; Braun, M.P. Effect of low temperatures on mortality of grasshopper eggs (Orthoptera: Acrididae). Can. Entomol. 1988, 120, 1147-1148. [CrossRef]

79. Lamb, R.J.; Turnock, W.J.; Hayhoe, H.N. Winter survival and outbreaks of bertha armyworm, Mamestra conjigurarta (Lepidoptera: Noctuidae) on canola. Can. Entomol. 1985, 117, 727-736. [CrossRef]

80. Kobayashi, S.; Ide, M.; Higashi, O. Overwintering of the rice weevil, Lissorhoptrus oryzophilus Kuschel (Coleoptera: Curculionidae) under snow and freezing conditions at a high elevation. Jpn. J. Appl. Entomol. Zool. 1988, 29, 45-49. [CrossRef]

81. Boulétreau-Merle, J.; Fouillet, P. How to overwinter and be a founder: Egg-retention phenotypes and mating status in Drosophila melanogaster. Evol. Ecol. 2002, 16, 309-332. [CrossRef]

82. Ryan, G.D.; Emiljanowicz, L.; Wilkinson, F.; Kornya, M.; Newman, J.A. Thermal Tolerances of the Spotted-Wing Drosophila Drosophila suzukii (Diptera: Drosophilidae). J. Econ. Entomol. 2016, 109, 746-752. [CrossRef] [PubMed]

(C) 2018 by the authors. Licensee MDPI, Basel, Switzerland. This article is an open access article distributed under the terms and conditions of the Creative Commons Attribution (CC BY) license (http:/ / creativecommons.org/licenses/by/4.0/). 